\title{
USO DA ÁGUA NA IRRIGAÇÃO
}

\section{Ramilos Rodrigues de Brito ${ }^{1}$}

\author{
Edilson Ramos Gomes ${ }^{2}$
}

\author{
Rafael Ludwig ${ }^{3}$
}

RESUMO: O presente trabalho procurou discutir os pressupostos teóricos, considerados em relação: a questão da preocupação com a utilização da água na irrigação, que é um recurso natural cada vez mais limitado; a questão da sustentabilidade, em especial a água residuária; e a questão do meio ambiente e sua valoração. A metodologia utilizada foi uma revisão de literatura através de documentos oficiais; publicações de revistas, jornais, artigos; documentos institucionais; além de fontes estatísticas e outros tipos de material literário que contribuísse para o enriquecimento deste estudo.

Palavras-chave: Água residuária. Manejo. Eficiência.

\section{1. ÁGUA: IMPORTÂNCIA E PROBLEMÁTICA}

\footnotetext{
${ }^{1}$ Eng. Agrônomo, Mestrando em Agronomia (Irrigação e Drenagem), UNESP/FCA - SP. E-mail: ramilos@hotmail.com.

${ }^{2}$ Eng. Agrônomo, Mestrando em Agronomia (Irrigação e Drenagem), UNESP/FCA - SP.

${ }^{3}$ Eng. Agrícola, Doutorando em Agronomia (Irrigação e Drenagem), UNESP/FCA - SP.
} 


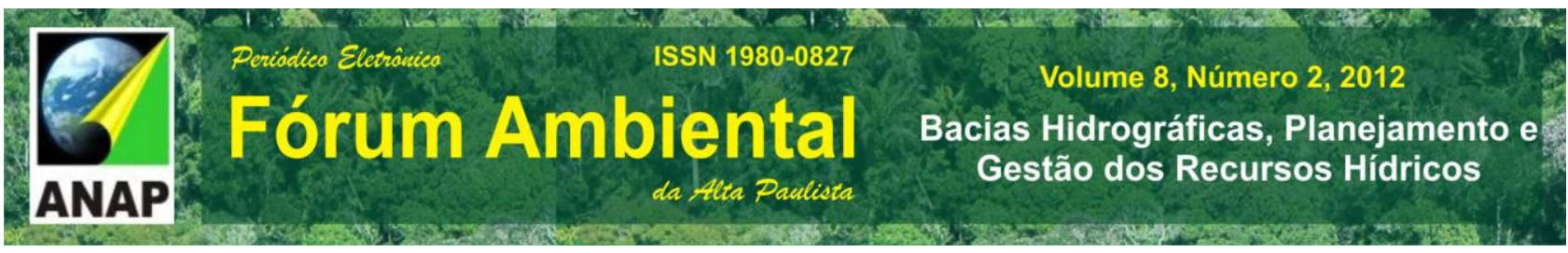

A água mostra-se como tema para grandes preocupações nos dias atuais pelo elevado desperdício, bem como pela qualidade, que está sendo progressivamente prejudicada por influência humana.

A qualidade é tão importante quanto à quantidade, quando está relacionada a atender as necessidades básicas dos seres humanos e do meio ambiente. Ela é fonte da vida, não importa o que fazemos, onde vivemos, dependemos dela para sobreviver. No entanto, por maior que seja sua importância, as pessoas continuam, ainda, poluindo os rios e suas nascentes, esquecendo o quanto ela é essencial.

Ela é provavelmente o único recurso natural que tem a ver com todos os aspectos da civilização humana, desde o desenvolvimento agrícola e industrial aos valores culturais e religiosos arraigados na sociedade.

A figura 1 mostra como a água se encontra distribuída no planeta. A água do mar (não potável) é representada por $97 \%$; a água doce, porém congelada corresponde a $2,5 \%$; e a água doce e disponível é representada por apenas $0,5 \%$. Esses $0,5 \%$ estão divididos em escala decrescente em aquíferos, chuvas, lagos natural, reservatórios e rios.

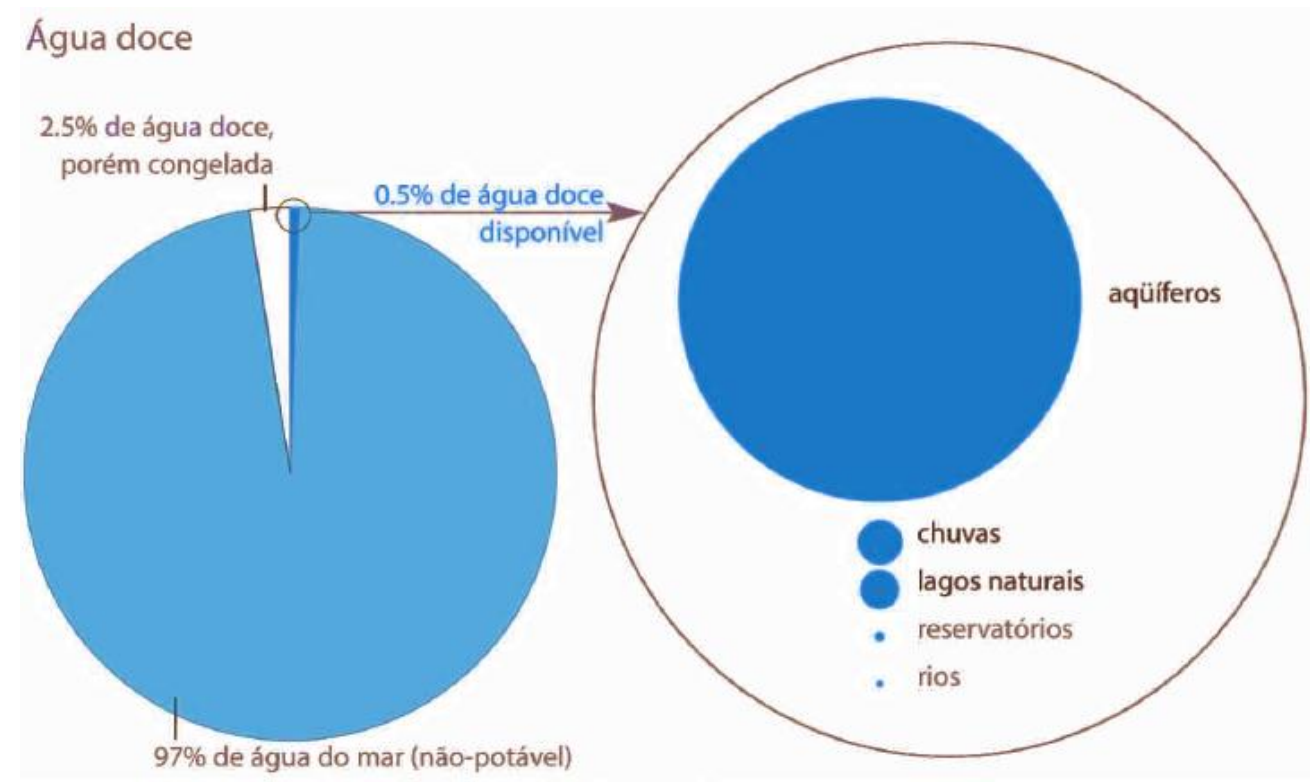

Figura 1. Situação da água doce no mundo. Fonte ANA

Cerca de $70 \%$ da superfície da terrestre estão ocupadas por oceanos, estes constituem $97 \%$ da água existente no planeta, sendo responsáveis por redistribuir calor e água através das correntes marinhas. Os rios exercem as mesmas funções num campo mais limitado e com maior interação com a terra. A distribuição de calor e água nos 
oceanos é função de forças dos ventos, rotação da Terra, topografia oceânica, e dos fatores salinidade, temperatura, pressão e densidade da água, com importância crucial nas trocas entre a atmosfera, a superfície da água e o fundo dos oceanos. No ar e nas águas, estes processos são mais intensos, fazendo com que estes meios tenham maior capacidade de influir no clima.

Dentro do corpo humano essa substância é o principal constituinte das células, estando presente nos processos bioquímicos, desde a regulação da temperatura corporal, até o transporte de oxigénio e nutrientes para as células. Por isso, quando não há água ou quando esta é escassa, o transporte vital de energia e de outros elementos indispensáveis é imediatamente comprometido.

O crescimento populacional e a demanda por melhor qualidade de vida comprimem o alicerce de recursos naturais, sendo um grande desafio a ser encarado, que é o de assegurar o acesso e uso sustentável desses recursos no processo da evolução do ser humano.

A diminuição dos desperdícios, dos impactos ambientais e a utilização adequada dos recursos assegurarão que os processos de esgotamento ultimamente notados sejam revertidos, possibilitando sua disponibilidade para futuras gerações.

\subsection{PANORÂMICA DA ÁGUA NO BRASIL}

O Brasil apresenta uma conjuntura confortável quanto à disponibilidade hídrica, segundo a ANA (2012), 12\% da disponibilidade do planeta. Mas toda essa disponibilidade encontra-se distribuído irregularmente no território brasileiro. A Região Hidrográfica Amazônica é a que apresenta a maior disponibilidade do país, e é inversamente proporcional ao contingente populacional, ou seja, $80 \%$ da disponibilidade hídrica estão concentrados onde está o menor número de pessoas.

A região Nordeste, diferentemente da Amazônica, apresenta chuvas irregulares, clima adverso e para tentar minimizar toda essa situação são construídos reservatórios artificiais, que possuem papel estratégico para a sobrevivência da população. Os reservatórios cumprem a função de armazenar água no período chuvoso para a garantia de água em períodos de seca. A ANA (2012) mostra que em 2011 houve um aumento de 
9\% no volume armazenado na região Nordeste, em relação a 2010. Entretanto, a análise por estado revela que o estado da Bahia apresentava em dezembro de 2011 valores de volume estocado bem abaixo da média da região (42\% da capacidade contra $68 \%$ da região Nordeste).

Um levantamento dos principais reservatórios artificiais brasileiro, realizado pela Agência Nacional de Águas (2011) determinou o volume reservado per capita do País e por região hidrográfica. Foi verificado que o Brasil possui $3.607 \mathrm{~m}^{3}$ armazenados em reservatórios artificiais por habitante. Esse número é quase três vezes maior que a quantidade de água armazenadas em outros continentes, como Europa, $1.486 \mathrm{~m}^{3} / \mathrm{hab}$; América Central e Caribe, 836 m³/hab; e Ásia, 353 m³/hab.

\subsection{CONTAMINANTES DAS ÁGUAS}

As atividades humanas e os processos naturais alteram as características químicas, físicas e biológicas da água, com potencial prejuízo para a saúde humana e do ecossistema. A qualidade da água é afetada por alterações em teores de nutrientes, sedimentos, temperatura, $\mathrm{pH}$, metais pesados, toxinas não metálicas, componentes orgânicos persistentes e agrotóxicos, fatores biológicos, entre muitos outros (Carr e Neary, 2008).

A contaminação por excesso de nutrientes tornou-se o problema de qualidade da água mais comum em todo o planeta (UN WWAP, 2009). Os principais elementos incluídos nesse contexto são nitrogênio e fósforo, por serem provenientes da agricultura, do lançamento de resíduos residenciais e industriais. Essa grande quantidade de matéria orgânica prontamente disponível nos rios proporciona o supercrescimento de plantas vasculares, a aflorações de algas e ao esgotamento do oxigênio dissolvido na coluna de água, o que pode provocar estresse ou mesmo matar organismos aquáticos.

Em várias regiões, as atividades humanas modificam a velocidade de erosão natural, mudando expressivamente o volume, a taxa e o momento da inserção de sedimentos nos rios e lagos, assim comprometendo as adaptações das espécies aos regimes de sedimentação preexistentes. 


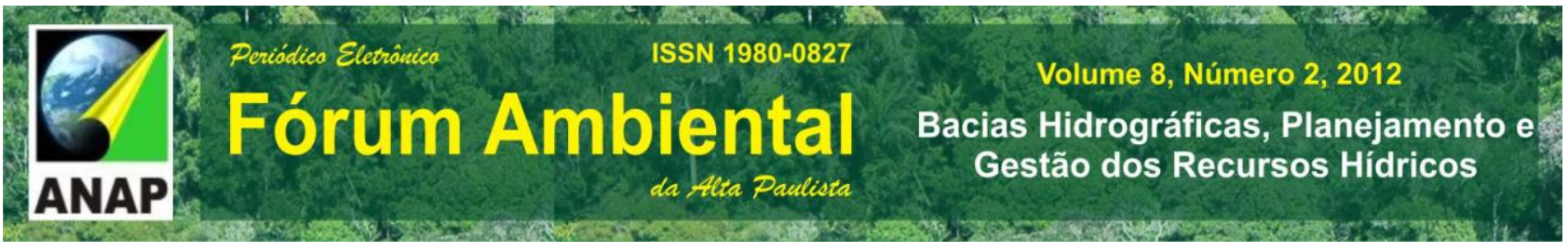

$\mathrm{O} \mathrm{pH}$ de diferentes ecossistemas aquáticos determina a saúde e as características biológicas deles. Um complexo de atividades industriais, com destaque para a mineração, pode provocar acidificação em sistemas pluviais.

A acidificação afeta desproporcionalmente organismos púberes que tendem a ser menos tolerantes ao baixo pH. A lixiviação da água de irrigação, as descargas de águas subterrâneas de perfurações de petróleo e gás, diversas atividades industriais; águas residuárias provenientes de tratamento municipal de água entre outros, elevam os teores de sais. E esse incremento pode provocar estresse em organismos de água doce, danificando a função fisiológica e os níveis de oxigênio. Pode também alterar a vegetação ribeirinha e emergente, afetar as características das terras úmidas e pântanos naturais, diminuir o habitat de algumas espécies aquáticas e reduzir a produtividade agrícola e de certos cultivos (Carr e Neary, 2008).

Desde a década de 1970, é cada vez maior a preocupação com os aumentos de escoamento de resíduos de nitrogênio, fósforo e agrotóxicos nas águas superficiais e subterrâneas. É sabido, há muito tempo, que os sistemas de cultivo intensivo, a crescente concentração de pecuária confinada em "fábricas" e as operações da aquicultura podem contribuir para a poluição difusa de águas superficiais e subterrâneas. (Ignazi, 1993)

De todos os insumos agrícolas que mais contribuem para a poluição das águas, os fertilizantes químicos e os agroquímicos têm especial destaque pela larga utilização, sendo considerável a dependência de insumos químicos na agricultura atualmente.

O fósforo $(\mathrm{P})$, o amônio $\left(\mathrm{NH}_{4}^{+}\right)$e o potássio $(\mathrm{K})$ são os fertilizantes mais utilizados nos cultivos agrícolas e quando utilizados em excesso costumam infiltrar-se no solo, seguindo até as águas subterrâneas pela lixiviação do solo, ou atingindo os corpos d’água superficiais. O fósforo, pelas suas características químicas, tende a infiltrar menos e fica mais nas águas superficiais, que são também atingidas pelos demais nutrientes, ocorrendo a eutrofização da água e os desequilíbrios ecológicos decorrentes.

\section{USO DA ÁGUA NA IRRIGAÇÃO}

As demandas da humanidade relacionadas com o aquecimento global, a necessidade de reduzir o dióxido de carbono da atmosfera, novas fontes de energia, a 
erosão de solos, a crise da água e outras ameaças sobre recursos naturais determinaram novo perfil para a agricultura.

A água, as árvores e o solo são, cada vez mais, considerados bens da humanidade. E o produtor acaba se tornando um administrador certificado para o uso e o manejo dos recursos naturais. A produção de alimentos não é mais utilizando técnicas queima, de plantio com animais; ela passa a ser um negócio competitivo, controlada pelo mercado e regulamentada por legislações ambientais e sanitárias rigorosas.

A grande parte dos alimentos utilizados para a nutrição da população é proveniente da agricultura. E até o momento não há maneiras que garantam a sobrevivência senão continuar cultivando o solo, e utilizar seus produtos como alimento.

A figura 2 apresenta a estimativa realizada pela Agência Nacional de Águas (2012), das demandas hídricas por tipo de uso, tendo como 2010 o ano base. A maior vazão de retirada foi para o emprego na irrigação, $1.270 \mathrm{~m}^{3} / \mathrm{s}$, correspondente a $54 \%$, em segundo lugar está a retirada de água para fins de abastecimento humano urbano, cuja vazão de retirada foi de $522 \mathrm{~m}^{3} / \mathrm{s}$, compondo $22 \%$ do total. Com relação à vazão efetivamente consumida, $72 \%$ correspondem à demanda de irrigação, seguida da utilização para suprimento animal (11\%), abastecimento urbano (9\%), abastecimento industrial (7\%) e abastecimento rural (1\%). Percebe-se que há uma grande ineficiência no sistema, pois a vazão retirada é de $2.373 \mathrm{~m}^{3} / \mathrm{s}$ e a vazão consumida é de $1.212 \mathrm{~m}^{3} / \mathrm{s}$, ou seja, é utilizado apenas $51 \%$ da vazão de retirada. 

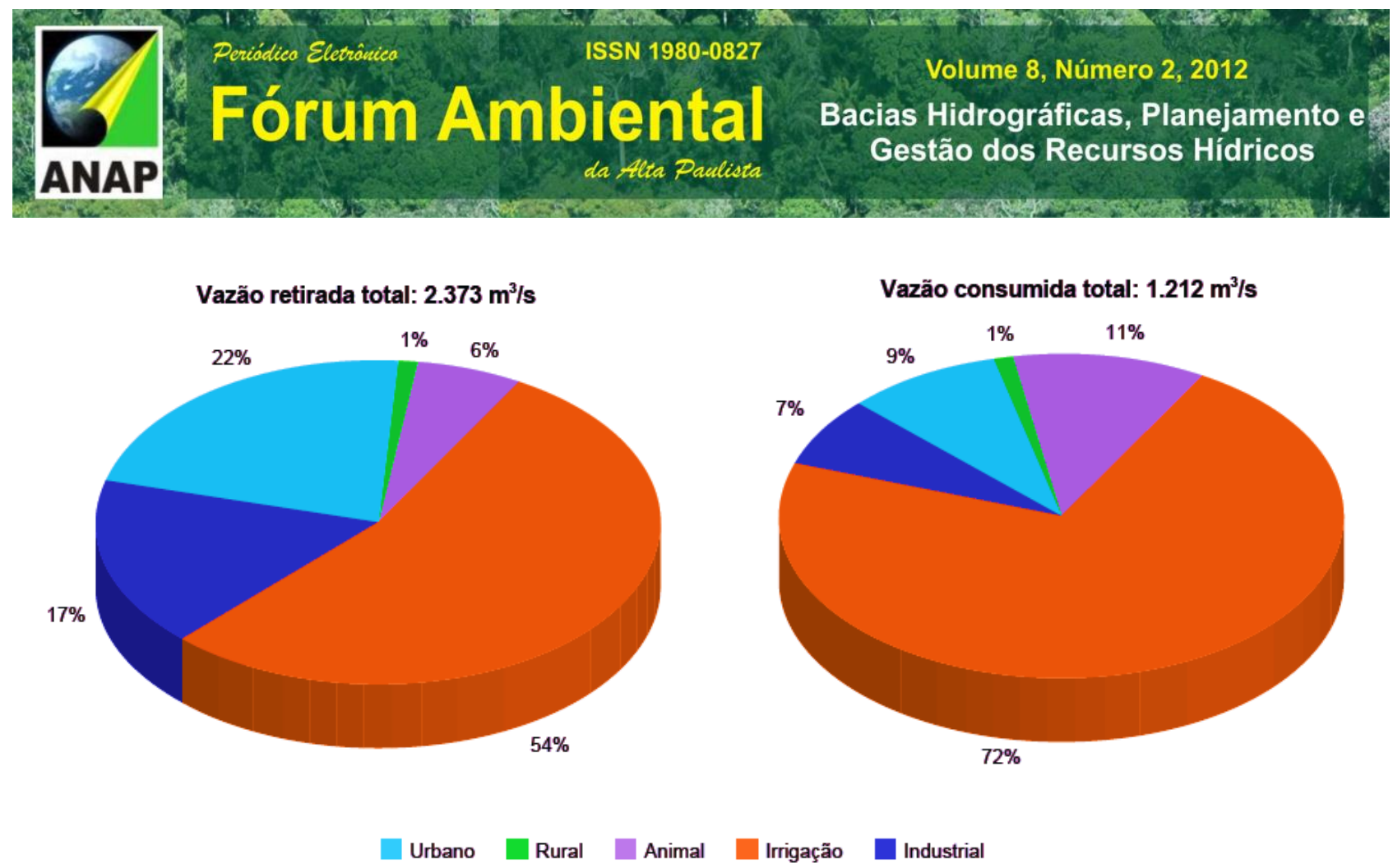

Figura 2. Estimativa das demandas por tipo de uso consuntivo de recursos hídricos em 2010. Fonte: ANA 2012.

$\mathrm{Na}$ irrigação a grande problemática são os baixos índices de eficiência, devido a diversos fatores técnicos, climatológicos, de manejo do solo e dos cultivos. As perdas por evaporação e lixiviação são consideráveis. A palavra chave é maximização da eficiência de utilização de água, aumentando-se o seu rendimento econômico, pois em tempos remotos o setor que será mais prejudicado pela escassez do recurso em quantidade e qualidade, será o agrícola.

A eficiência de irrigação, tomada como a razão entre a quantidade de água efetivamente usada pela cultura e a quantidade retirada da fonte, no âmbito mundial, é ainda muito baixa, situando-se, em termos médios, em torno de $37 \% \%$ (LIMA et.al, 1999).

A simples melhora de $1 \%$ na eficiência do uso da água de irrigação, nos países em desenvolvimento de clima semiárido ou árido, significaria uma economia de 200 mil litros de água, por agricultor, por hectare/ano. A irrigação utilizada de forma racional pode promover uma economia de aproximadamente $20 \%$ da água e $30 \%$ da energia consumida. Do valor relativo à energia, a economia de $20 \%$ seria devido à não aplicação excessiva da água e $10 \%$ devido ao redimensionamento e otimização dos equipamentos utilizados (LIMA et.al, 1999). 


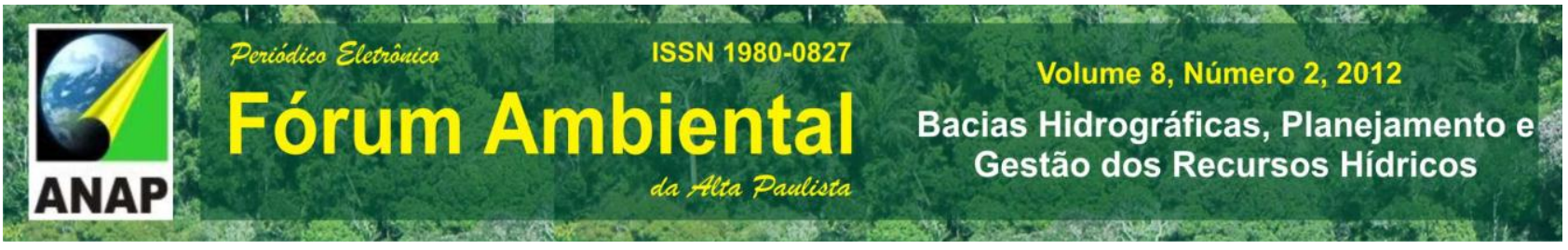

Já sabemos que a irrigação é sabidamente o maior usuário de água no Brasil e a estimativa da área irrigável é da ordem de 29,6 milhões de hectares (CHRISTOFIDIS, 2005). Apesar de a agricultura irrigada ser o principal uso consuntivo no País e, por isso, requerer maior atenção dos órgãos gestores, visando ao uso racional da água, ela resulta em aumento da oferta de alimentos e preços menores em relação àqueles produzidos em áreas não irrigadas, devido ao aumento substancial da produtividade. Especialmente nas regiões onde o déficit hídrico é significativo, a irrigação constitui-se em fator essencial para a produção agrícola. (ANA, 2011)

Atualmente, encontram-se operando, implantados ou em implantação, 319 mil hectares de área irrigada, sendo que $54 \%$ desse valor já são cultivados. Destacam-se os Projetos Arroio Duro, Senador Nilo Coelho, Caraíbas/Fulgêncio, Ico-Mandantes, Curaçá, Tourão e Pedra Branca, que possuem área total superior a 10.000 ha, com situação de implantação acima de $85 \%$. Além desses, novos perímetros de irrigação encontra-se em estudo, tal como o Programa de Desenvolvimento do Sudoeste do Tocantins (Prodoeste), na Bacia do Rio Tocantins-Araguaia, que prevê uma área de 303 mil hectares. (ANA, 2011)

A progressiva competição pelos recursos hídricos restringirá sua disponibilidade para uso na irrigação, consequentemente irá limitar gravemente a produção de alimentos no mundo. O decaimento na produtividade de alimentos suscitará numa absoluta elevação de preços. Já sabemos que a desigualdade social é perceptível em nosso país, e o esgotamento desse recurso iria aumentar significamente a desnutrição.

A água utilizada na agricultura pode ser de qualidade inferior à da água empregada para usos residenciais e industriais. No entanto, em alguns casos a água pode passar por tratamento. Cada vez mais, as áreas agrícolas estão recorrendo a águas recicladas como nova fonte resistente a secas. Em alguns países, foram estabelecidas normas para assegurar que a água reciclada é segura para usos agrícolas.

WHO (1989) cita vantagens do reuso de águas: a recuperação e a economia de água, o alto poder fertilizante do efluente, a formação de húmus e a redução ou eliminação da poluição ambiental.

O emprego de água residuária na irrigação pode reduzir os custos de fertilização das culturas, bem como o nível requerido de purificação do efluente e, 


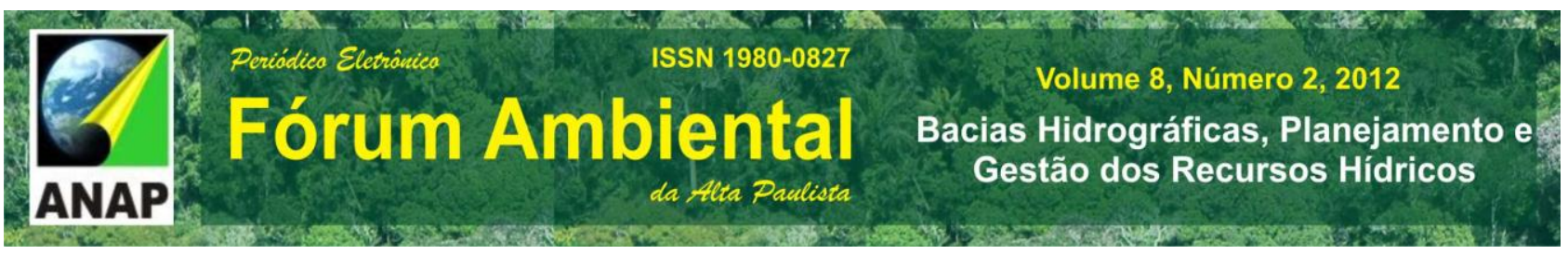

consequentemente, os custos de seu tratamento, já que as águas residuárias contêm nutrientes e o solo e as culturas comportam-se como biofiltros naturais (HARUVY, 1997; BRANDÃO et al., 2002).

Dessa maneira, o uso de água residuária para diversos fins, incluindo o da irrigação, aparece como alternativa para aumentar a oferta de água, assegurando a economia do recurso e racionalização do uso desse bem. Alguns países já empregam essa tecnologia e possuem regulamentação específica de usabilidade. Contudo o Brasil ainda está em fase embrionária na efetivação e regulamentação da técnica, com grande potencial de crescimento.

Duarte (2007) comenta que os custos da água reciclada são baixos quando comparados àqueles de outras fontes não convencionais e envolvem as necessidades de adaptação do efluente ao objetivo agrícola. Mas para isso, o efluente deve sofrer um tratamento, depois ser armazenado e transportado para as áreas de produção agrícola. Esses processos apresentam custos variáveis que devem ser calculados para obtenção do custo total da água de reuso na agricultura.

Dessa somatória de custo de produção da água reciclada deve ser deduzido o custo o custo necessário para tratamento do efluente que atenda as normas ambientais, caso se optasse por sua disposição direta nos corpos d'água ao invés de se reutilizar na agricultura, e o custo referente à economia na fertilização do solo, uma vez que a água residuária contém diversos nutrientes.

Quanto menor o custo de tratamento da água residuária, maior a lucratividade e atratividade desta fonte de água para a agricultura. $\mathrm{O}$ esgoto urbano deve ser tratado para ser utilizado na irrigação, mas seu tratamento também é obrigatório para disposição direta nos corpos d'água. Os benefícios do reuso da água na agricultura são expressos quando a produção agrícola é mantida, enquanto as fontes de água e o meio ambiente são preservados (HARUVY, 1997).

\section{CONSIDERAÇÕES FINAIS}

Ainda que os benefícios provenientes da utilização da irrigação sejam inegáveis, é necessário saber que os projetos de irrigação podem causar impactos desfavoráveis ao 
meio ambiente, à qualidade do solo e água, à saúde pública e ao aspecto socioeconômico da região.

Uma possível solução para essa problemática do uso da água é uma gestão de controle e conservação de seu uso. Essa gestão deve ser realizada de forma multidisciplinar, não deve ser analisada apenas na visão da irrigação, ou da geração de energia elétrica, ou saneamento básico, mas sim na sua totalidade.

Pelos motivos supracitados, os projetos hidráulicos devem considerar obrigatoriamente o uso múltiplo da água e segundo análises sociais, econômicas e ambientais, devem-se estabelecer as potencialidades de cada um desses usos, com os devidos planejamentos e regulamentações necessárias para o uso racional dos recursos hídricos, visando sempre o melhor para o bem-estar de nossa nação.

\section{REFERÊNCIAS}

Agência Nacional de Águas. Conjuntura dos recursos hídricos no Brasil: informe 2012. Ed. Especial. 215 p. Brasília: ANA, 2012.

Agência Nacional de Águas. Cuidando das águas: soluções para melhorar a qualidade dos recursos hídricos; Programa das Nações Unidas para o Meio Ambiente. Brasília: ANA, 154 p. 2011.

BRANDAO, L. P.; MOTA, S.; MAIA, L. F.. Perspectivas do Uso de Efluentes de Lagoas de Estabilização em Irrigação. In: VI Simpósio Ítalo Brasileiro de Engenharia Sanitária e Ambiental, 2002, Vitória, ES. Anais do VI SIBESA. Rio de Janeiro: ABES, 2002.

CARR, G.M. AND J.P. NEARY. Water Quality for Ecosystem and Human Health, $2^{\underline{a}}$ Edition. United Nations Environment Programme Global Environment Monitoring System. 2008 Disponível em: < http://www.gemswater.org/publications/ pdfs/water_quality_human_health.pdf.> Acessado em 19/09/2012.

CHRISTOFIDIS, Demetrios. Água e agricultura. Brasília: Ministério da Integração Nacional, 2005 (Série Irrigação e Água). Disponível em:<http://www.irrigacao.org.br/ artigos/Christofidis_Aguaeagricultura_Plenarium_2005.pdf>. Acessado em: 01/09/212

Duarte, A. S. Reuso de água residuária tratada na irrigação da cultura do pimentão (Capsicum annun L.). Piracicaba: ESALQ/USP, 2007. 187p. 
HARUVY, N. Agricultural reuse of wastewater: nation-wide cost-benefit analysis.

Agriculture, Ecosystems and Environment, Amsterdam, v. 66, p.133-119, 1997.

IGNAZI, J.C. Improving nitrogen management in irrigated, intensely cultivated areas: The approach in France in: Prevention of Water Pollution by Agriculture and Related Activities. Proceedings of the FAO Expert Consultation, Santiago, Chile. Water Report 1. FAO, Rome: 247-261.1993.

LIMA, J. E. F. W.; FERREIRA, R. S. A.; CHRISTOFIDIS,D. O uso da irrigação no Brasil: O estado das águas no Brasil. Brasília: Agência Nacional de Energia Elétrica, 1999.

Disponível em: <http://www.iica.org.uy>. Acesso em: 01/09/2012.

United Nations World Water Assessment Programme (UNWWAP). (2009). United Nations World Water Assessment Programme. The World Water Development Report 3: Water in a Changing World. UNESCO: Paris, France. Disponível em: <http://www.unesco.org/water /wwap/wwdr/wwdr3/.> Acessado em: 19/09/212

WHO - WORLD HEALTH ORGANIZATION. Health guidelines for the use of wastewater in agriculture and aquaculture: report of a WHO scientific group. Geneva, 1989. 74p. (WHO Technical Report Series, 778). 